\title{
INTERACTIONS OF THE HORIZONTAL AND VERTICAL HUMAN OCULOMOTOR SYSTEMS: THE SACCADIC SYSTEMS
}

\author{
ROBERT FeINSTEIN ${ }^{1}$ and William J. Williams ${ }^{2}$ \\ Bioelectrical Sciences Laboratory, University of Michigan, Ann Arbor, Michigan 48104, U.S.A.
}

(Received 20 April 1971; in revised form 20 May 1971)

\section{INTRODUCTION}

ONE OF the oldest ideas in experimental psychology is that the time between stimulus and response is occupied by a train of processes or stages-some being mental operationswhich are arranged so that one process does not begin until the preceding one has ended. This stage theory implies that the reaction time (RT) is a sum composed of the durations of the stages in the series. According to this theory, if one could determine the component times that add together to make up the RT, one might be able to answer certain questions about the mental operations to which these stages correspond. The study of RT should, therefore, prove helpful to an understanding of the structure of mental activity.

For the past $40 \mathrm{yr}$, researchers in human performance theory have been concerned with the phenomenon which occurs in reactions to stimuli separated by short time intervals (SMITH, 1967). The greatest effort has been directed toward studying the psychological refractory period (PRP). The PRP is the increase in the reaction time to a signal which closely follows another signal. When two stimuli are presented in rapid succession, the reaction time to the second stimulus ( $\mathrm{S} 2$ ) is typically prolonged compared with the reaction time to $\mathbf{S 2}$ when it is presented alone or after a very long interval (WeLFoRD, 1952). This increase is maximal at the shortest values of interstimulus interval (ISI) and decreases as the ISI is increased, until at some value of ISI, no further delay is encountered.

The system studied in this investigation is the human oculomotor system. This system has been studied by numerous people for well over half a century. Since the visual system is our primary sensory input channel, it is important for us to know how information is processed by the system. However, the visual system in its entirety is a vastly complex system which involves a large portion of the central nervous system. A subsystem which serves the visual system is the eye movement control system. This.subsystem has received a great deal of attention in recent years, since its output, eye position and movement, is relatively easy to measure, and its input can be well specified. The function of the control system is to maintain the portion of greatest interest in the visual field on the area of greatest visual acuity, the fovea.

Most of the work which has been done on modeling the eye movement control system has involved only the horizontal eye movement control system. There are several obvious reasons for a preference of the horizontal system. Under normal conditions, the eye appears

\footnotetext{
1 Presently with the Marine Biomedical Institute, 200 University Blvd., Galveston, Texas 77550.

2 This research was supported by funds from the Highway Safety Research Institute, University of Michigan.
} 
as an ellipse with its major axis oriented in the horizontal plane. Based only on this information, it is obvious that larger amplitudes of horizontal than of vertical movements are observable. Another consideration which has led to an emphasis of the horizontal system is that in the primary position of gaze, one pair of the extraocular muscles lies in the horizontal plane of the eye (WOLF, 1968). Therefore, based on the greater observable horizontal range and the assumption of an independent extraocular muscle system for horizontal movements, horizontal eye movements seem easier to analyze. It is convenient to note that the assumption of extraocular horizontal independence has been verified (TAMLER, MARG, JAMPOLSKY and NAWRARZKI, 1959).

Much has been done in applying systems theory to describing the oculomotor control system (e.g. Robinson, 1964; Westheimer, 1954; Young, 1962; Young, Forster and VAN HouTTE, 1968; ZUBER, 1965). These investigations have drawn heavily upon-and contributed significantly to - the existing body of physiological knowledge of the oculomotor and visual systems. Although most of the research which has been done on the oculomotor control system has been concerned with only the horizontal eye movement system, this research investigates the relationship between the horizontal and vertical saccadic systems.

To reveal the relationship which exists between the horizontal and vertical saccadic systems, experiments consisted of presentation of sequential visual inputs. The use of this type of input necessitates considering sequential task reaction time phenomena and central information processing constraints. No previous work on eye movements has considered the role of various central information processing constraints which are inherent in the performance of certain sequential tasks.

\section{APPARATUS}

The method used to measure horizontal and vertical eye movements depended upon detection of the difference in diffuse reflected light from the limbus on both sides of one eye. Figure 1 shows the arrangement of light sources and photodetectors, mounted on a pair of glasses worn by the subject. It is clear from Fig. 1 that the amount of reflected light received by each photodetector is a function of the angle of gaze. By taking the differential output between the two detectors, the effects of any nonlinearities or change in ambient light or temperature were minimized. Since the entire apparatus was light and small enough to mount in glass
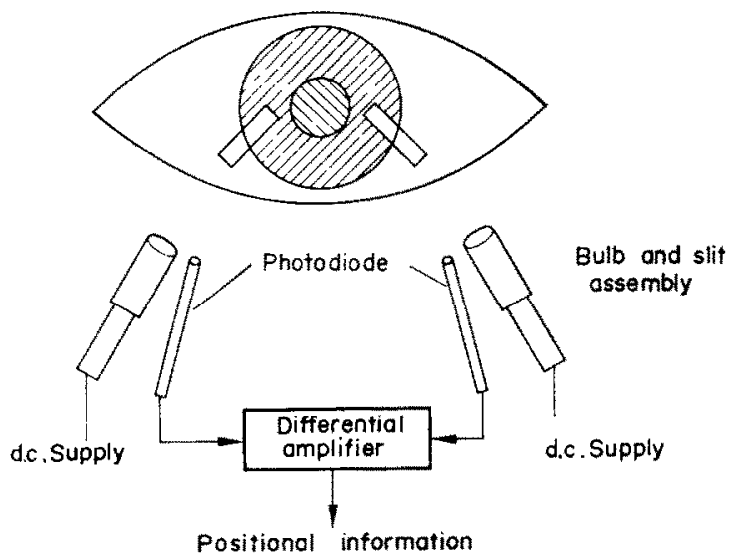

Frg. 1. Schematic representation of eye movement recording apparatus. The light bulb and slit assemblies were capped with Wratten No. 89B i.r. filters. The resultant slits of projected i.r. light were then reflected from the limbi and detected by the respective photodiodes (Texas Instruments No. LS 400). The resultant signals were processed as described in the text. 
frames, the monitor could record movements of the eye with respect to the head, independent of any head movements.

The light sources projected slits of light on the eye at an angle with respect to the horizontal. One slit was at an angle of approximately $45^{\circ}$ with the horizontal, while the other slit was at an angle of approximately $135^{\circ}$ with the horizontal. Since this research is concerned with temporal events and not with true positional information, little effort was made to achieve complete horizontal and vertical separation.

During calibration and cxpcrimental runs, the subject was seated with his head held immobile by the use of a bite bar rigidly supported by the chair in which the subject was seated. The chair was located at the center of curvature of a semicircular screen with a radius of $5 \mathrm{ft}$; the subject and screen were both contained in a light-proof booth. Also located at the center of curvature was the target projection system, which consisted of a $500 \mathrm{~W}$ slide projector and two Harvard Apparatus No. 350 recorder galvanometers. A 1 in. round front surface mirror was mounted on each galvanometer. The target was a well focused $1 / 4^{\circ}$ spot of light proected on the semicircular screen. The target projection system has a linear dynamic range of $\pm 40^{\circ}$ horizontal and $\pm 15^{\circ}$ vertical. The system frequency response was down $3 \mathrm{~dB}$ at $60 \mathrm{~Hz}$.

The input signals to the galvanometers were generated by a special purpose digital computer which was designed and built for this research. The computer produced a series of horizontal and vertical step functions, each series comprised of one horizontal and one vertical step. The computer determined the following:

(a) Whether a horizontal or vertical step was to occur first.

(b) A random interstimulus interval (ISI).

(c) A second step function dependent on the nature of the first, and

(d) If a horizontal step, then left or right, or if a vertical step, then up or down.

The decisions made by the computer could be preset to be random or deterministic in nature, i.e. random horizontal or vertical steps first with random ISI, or horizontal steps first with fixed ISI; all combinations of the above were possible.

\section{METHODS FOR EXPERIMENT 1}

There are several reasons that each of the various experimental paradigms was selected. The reader should keep in mind the fact that a moving spot of light is an irresistible stimulus when there is no other fixation point in the visual field.

It is well known that the eye movement system is an adaptive one capable of predictive tracking. The system characteristics in the predictive mode are not well understood and mainly involve use of the smooth pursuit system for predictive periodic target tracking (RoBINSON, 1965, 1968). Thus, to investigate the saccadic system, non-predictive aperiodic stimuli must be used. For this reason, a four-choice/two-choice experimental paradigm was chosen for Experiment 1. This paradigm results in a high degree of spatial and temporal uncertainty. The stimuli are step functions which evoke responses from the saccadic system only. Through observation of reaction times, the relationship between the horizontal and vertical saccadic systems should become evident.

The four-choice/two-choice paradigm consisted of a series of two target steps, each step having an amplitude of $6^{\circ}$ of visual field. The target was presented to the subject in such a manner that a vertical/ horizontal displacement from the primary position of gaze was delayed by a random amount of time from a horizontal/vertical displacement. The second (or delayed) displacement occurred while the initial displacement was still present, and both displacements were of sufficient duration to permit easy tracking by the subject. The duration of the first displacement was $1150 \mathrm{msec}$, and the second displacement was $200 \mathrm{msec}$ in duration. The order and direction of both displacements was also randomized, i.e. the target could move horizontally to the right or left and vertically up or down. Figure 2 is a diagram of a typical input sequence. A typical input might consist of a horizontal step to the right (point 1 of Fig. 2), followed after an ISI by a vertical step up. At this point in time, the target would be located at point 2 of Fig. 2 . The target would return to the horizontal right position (point 3 of Fig. 2), then would return to the starting position. Note that the following paths represented in Fig. 2 are equivalent:

$$
\begin{aligned}
\text { Starting point }-1 & =3-\text { Starting point } \\
1 \quad-2 & =2 \quad-3
\end{aligned}
$$

The time for the sequence just described would be approximately $1 \mathrm{sec}$. After a delay of approximately $3 \mathrm{sec}$ another target sequence would be presented. This input would be a non-predictive one, referred to as the four-choice/two-choice paradigm. A target sequence constitutes one experimental trial and thirty such trials comprise an experimental block of trials.

The data for Experiment 1 were obtained from three male subjects, J.H., W.O. and B.C., ranging in age from 19 to 21 yr. Each subject was run through 6 blocks of trials, each block given on a different day. Prior to each block, the eye movement apparatus was aligned and calibrated. The first block of trials served to 


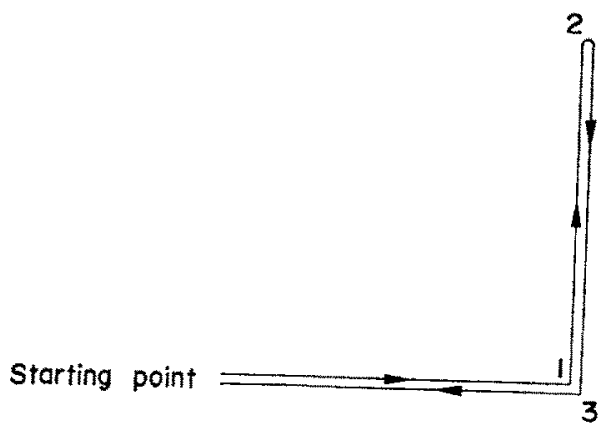

Fig. 2. A spatial representation of a typical target sequence. A typical target presentation might consist of the following events which are depicted here:

(1) At time zero the target, which consists of a well focused spot of light $1 / 4^{\circ}$ dia., is located at the primary position of gaze.

(2) The target jumps to position 1 , which in this case represents a $6^{\circ}$ right horizontal displacement from the primary position of gaze. After a random time delay, the target would then jump $6^{\circ}$ vertically to position 2 . At this point in time, the target would be $6^{\circ}$ up and $6^{\circ}$ to the right of the primary position of gaze.

(3) After approximately $200 \mathrm{msec}$ at position 2, the target would jump to position 3 and remain there until approximately 1150 msec after its initial movement at which time it would return to the starting position. Details regarding the utilization of these sequential stimuli are discussed in the text.

familiarize the subject with the apparatus and the experimental paradigm; no data were recorded for this block. In each of the remaining 5 blocks of trials, the first 10 trials were used to acquaint the subject with the paradigm, and the remaining twenty trials were recorded and used as data. No other experiments were run concurrently with this experiment. The subjects were instructed to follow the target as accurately and quickly as possible. In this experiment, the values of ISI were random from trial to trial. Three quantities were recorded for each trial: ISI, $R T_{1}$, and $R_{2}$. A fourth quantity, the System Delay $\left(R_{2} T_{2}-R_{1}\right)$ was computed for each trial. The raw data for each subject's 5 blocks of trials were processed by sorting them into bins 20 msec in width as a function of IST. Using a computer, the following calculations were made for each such bin: the number of points lying within the bin, the average value over that bin, and the standard deviation for that bin. These calculations were made for each of the dependent variables, ISI being the independent variable.

\section{RESULTS FOR EXPERIMENT 1}

A typical recording obtained using the four-choice/two-choice paradigm and the variables measured are shown in Fig. 3. In the experimental trial illustrated in Fig. 3, the vertical displacement occurred first, followed by a horizontal displacement in $740 \mathrm{msec}$. Figures 4, 5 and 6 represent plots of the averaged data for the three subjects for $\mathrm{RT}_{1}$ vs. ISI, $\mathrm{RT}_{2}$ vs. ISI and System Delay vs. ISI, respectively. Each point on these plots represents the average of at least 10 experimental trials.

It can be seen from Fig. 4 that there is little variation of $\mathrm{RT}_{1}$ as a function of ISI for all three of the subjects. The only differences among the three subjects are their individual mean reaction times. Figure 5 shows the relationship of $\mathrm{RT}_{2}$ vs. ISI for the three subjects. Again the results for all three subjects are similar, with the differences among the subjects again being in mean reaction times. Figure 6 is a plot of System Delay vs. ISI for the three subjects. This again points out the similarity among the three subjects.

Note that the range of the data shown in these figures is not uniform for all three subjects. In particular, W.O.'s data were obtained over a different period of time than those of the other two subjects. As a result, insufficient data were obtained at low values of ISI. It should also be noted that even though the results are plotted by points, they represent average values over 20 -msec intervals. 


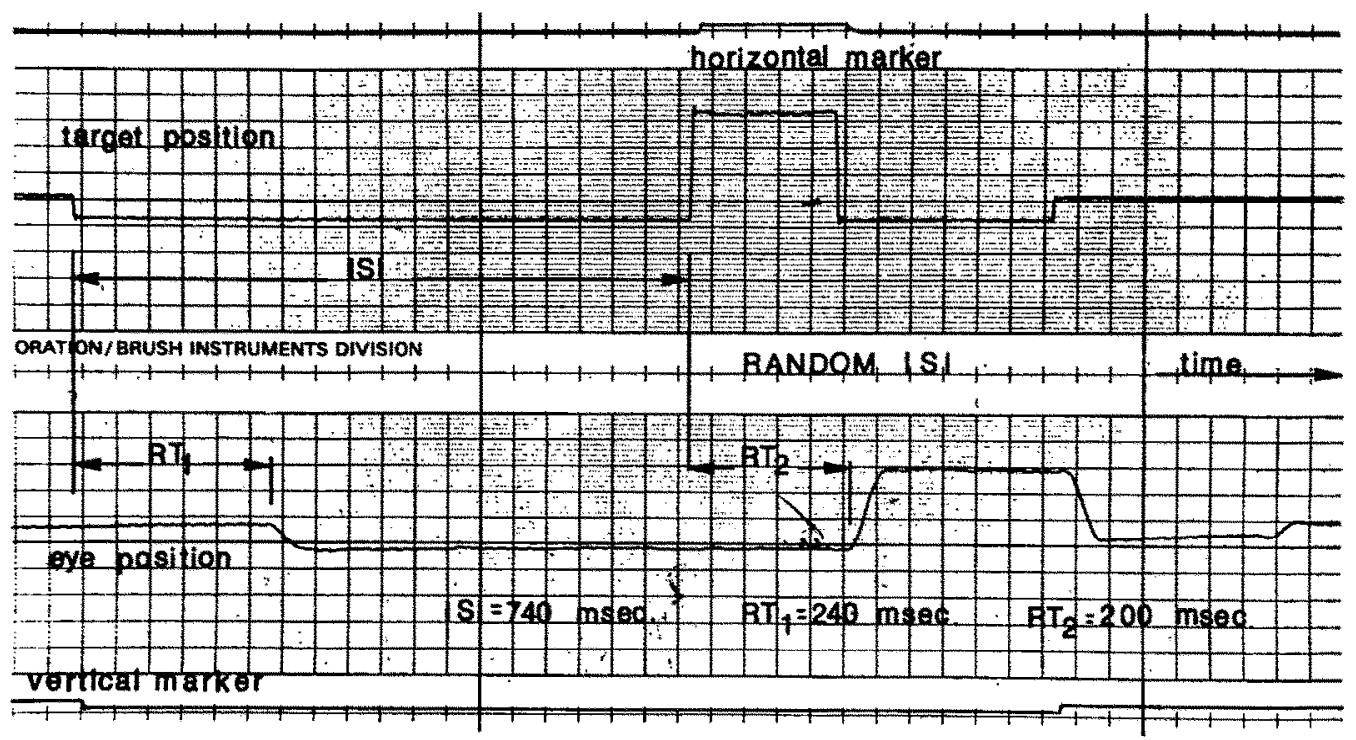

Frg. 3. A typical recording obtained using the four-choice/two-choice paradigm. The top most trace indicates the presence of a horizontal target step. The next trace represents the superimposed horizontal and vertical target displacements with the independent variable, ISI, being shown. The eye position record illustrates the definition of the two dependent variables, $R_{1}$ and $\mathrm{RT}_{2}$. The bottom most tracing indicates the presence of a vertical target step. Note the two distinct eye movements, which had previously been verified as being orthogonal movements for all values of ISI used.

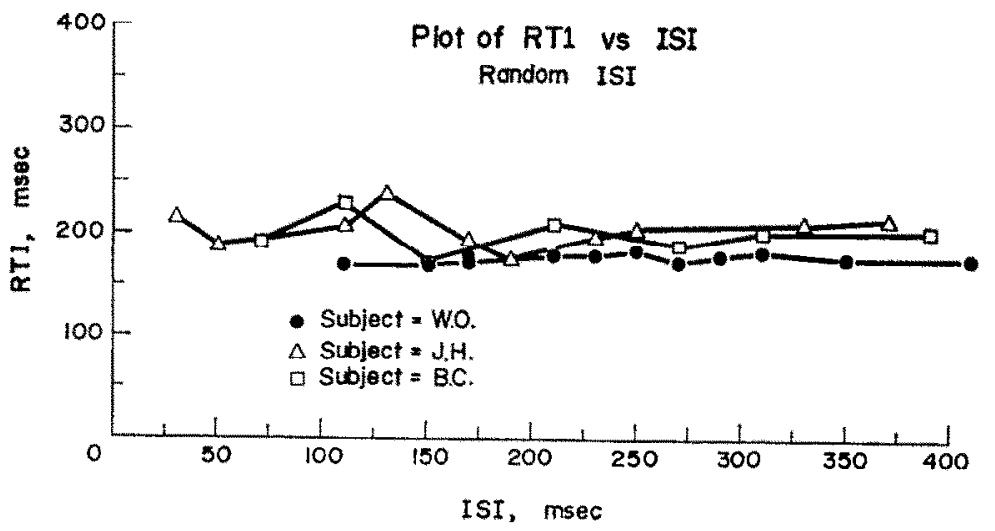

FrG. 4. Plot of RT, vs. ISI for Experiment 1. The results for the three subjects are shown here and in the remaining figures. Each point indicated by a symbol represents the mean value of the dependent variable, in this case $\mathrm{RT}_{1}$, for the corresponding value of ISI. It can be seen that there is little if any variation of $\mathrm{RT}_{1}$ as a function of ISI. Note that the symbol used for a given subject is used consistently in all figures and is shown in the symbol table included as part of each figure. 


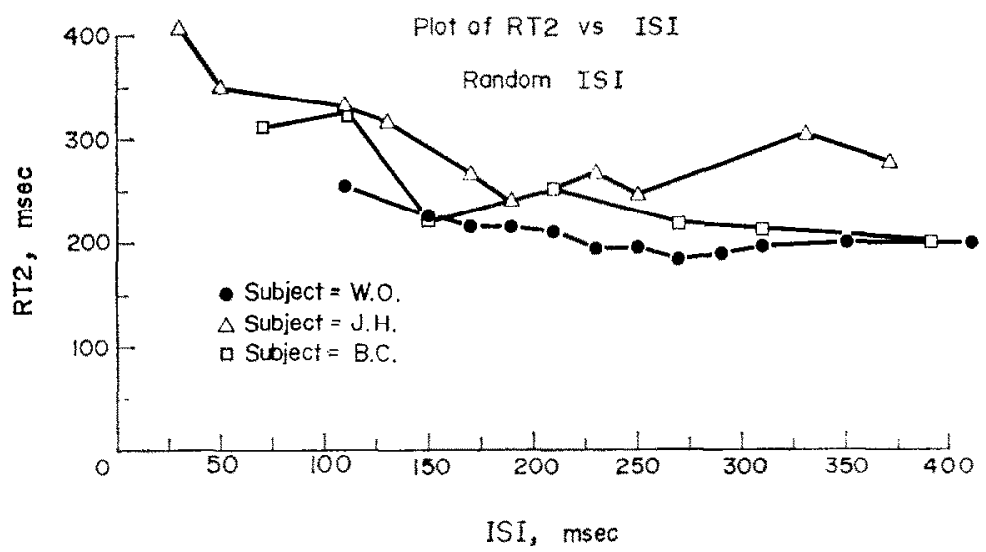

Fra. 5. Plot of RT 2 vs. ISI for Experiment 1. Unlike Fig. 4, the results shown here indicate that there is a substantial effect of ISI on $\mathrm{RT}_{2}$ for all subjects. The phenomenon observed here is known as the Psychological Refractory Period (PRP). Subject W.O.'s data do not extend to very low values of ISI, since his data were obtained at a later date.

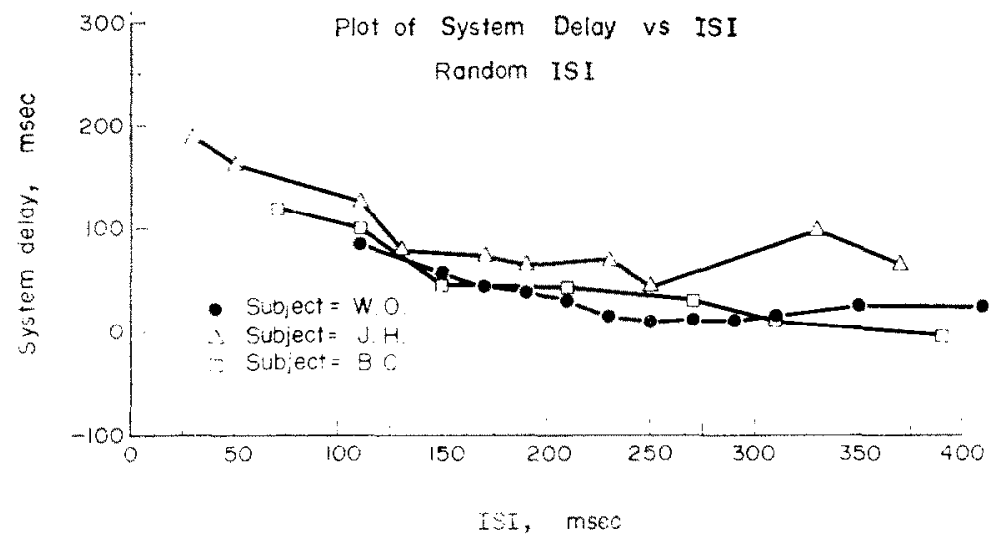

Fig. 6. Plot of System Delay vs. ISI for Experiment 1. The System Delay is defined as $R T_{2}-R_{1} T_{1}$. Thus if there were no interaction between the horizontal and vertical saccadic systems, the System Delay would be zero and not a function of ISI as is shown.

\section{DISCUSSION OF EXPERIMENT 1}

As a preface to the interpretation of the results of Experiment 1, let us consider some of the previously documented properties of the horizontal and vertical saccadic systems. As stated in the Introduction, most of the previous work on eye movements involved only the horizontal eye movement system. Of these various studies, there are several which are relevant to Experiment 1. The findings of BEELER (1965) and WHEELESS (1965) both alluded to the influence of central processing on horizontal eye tracking performance. Beeler found that the reaction time to the second of two sequential horizontal steps was a function of whether the two steps were in the same direction or in opposite directions. He found that reaction time to the second step was shorter when the second step was in the opposite 
direction from the first. He attributed this result to a physiological refractoriness. An analogous experiment was performed by Feinstein and WiLliams (1968). In that experiment the target moved first horizontally to the right and after a random delay, it moved vertically up or down. Another experiment was performed in which the target moved just vertically up and after a random delay, horizontally left or right. No significant difference in reaction times was noted between the data for horizontal first and vertical first. Furthermore, in a recent paper by ST-CYR and FENDER (1969) they reported little interaction between horizontal and vertical eye movements.

WHEELESs" (1965) experiment involved the use of a "pulse step" target function. $\mathrm{He}$ varied the width of a pulse which was superimposed on a target step and determined the reaction time. He found that the subject responded both to the pulse and step and to the step only. This behavior was a function of the pulse width, i.e. for pulse widths of $50 \mathrm{msec}$ the subject responded to both stimuli only 8 per cent of the time. The results of his experiments indicated a role for central information processing other than that of mimicking target movements. This aspect of eye movements has been shown before (CoOK, 1965; ZUBER, 1965) and has been taken as an indication that the eye movement system samples the visual information; however, Wheeless gives evidence that sampling as previously proposed by Young (1962) cannot adequately describe performance to pulse-step targets.

Let us now consider the results obtained in Experiment 1. Figure 4 indicates that there is no significant effect of $\mathrm{S} 2$ on $\mathrm{RT}_{1}$. This result differs from the findings in some manual reaction time tasks, (TrIGGs, 1968). The effect found in manual reaction time tasks may be due to the fact that in these tasks, a much larger part of the CNS is utilized. In eye movement studies, only one sensory motor system is in use. Figure 4 indicates a degree of parallel processing; otherwise, one would expect a second input to influence the first.

Figure 5 shows the relationship between $\mathrm{RT}_{2}$ and ISI. The phenomenon illustrated by these results is similar to the psychological refractory period, PRP, which has been reported previously for manual reaction time studies, (TrigGs, 1968). The only significant difference between the results shown in Fig. 5 and those reported for manual tasks is the task reaction time. Eye movement reaction times are approximately $100 \mathrm{msec}$ faster than manual task reaction times. For values of ISI greater than $250 \mathrm{msec}$, the values for $\mathrm{RT}_{2}$ approach those of $\mathrm{RT}_{1}$. It should be pointed out that the values obtained for $\mathrm{RT}_{1}$ correspond to simple reaction times obtained for single step presentations. Thus, for ISI's shorter than $250 \mathrm{msec}$, the subject's reaction time to $\mathrm{S} 2$ is affected by $\mathrm{S}_{1}$. As discussed in the manual reaction time literature (e.g. Triggs, 1968; WeLFoRd, 1952), the presence of the PRP indicates that serial information processing is involved, which implies that the vertical and horizontal saccadic systems share a common information processing unit.

Figure 6 shows the results of System Delay vs. ISI for Experiment 1. This plot is similar to Fig. 5 except that compensation has been provided for variations of $\mathrm{RT}_{1}$ vs. ISI.

\section{METHODS FOR EXPERIMENT 2}

The use of the four-choice/two-choice paradigm introduces one possible objection: the subject knows that once the target has moved horizontally, it will then move vertically, or vice versa. This might result in the subject's anticipating the second input and thereby doing some unwarranted preprocessing. To determine whether or not this phenomenon was present in Experiment 1, a second experiment was performed in which the first stimulus $\left(\mathbf{S}_{1}\right)$ was predetermined as being horizontal, and the value of ISI was fixed, thereby creating an extreme of the situation which might have existed in Experiment 1. This procedure, known as the twochoice/two-choice paradigm was used to serve as a cross-check on Experiment 1 . The combined results of these two experiments enable one to determine whether predictive tracking was involved in either of them. 
The data for Experiment 2 were obtained from 3 male subjects, J.H., J.M. and W.O., ranging in age from 19 to $21 \mathrm{yr}$. Each subject was run through 6 groups of 8 blocks for each value of ISI used. These fixed values of ISI were (in msec): $50,100,125,150,175,200,300$ and 400 . Each of the 8 blocks of trials had a different fixed value of ISI. One group of blocks was given to each subject on a different day; however, on these days, the subjects also participated in other experiments. One initial group of blocks was administered to each subject in order to familiarize him with the apparatus and the experimental paradigm; no data were recorded for this group. For the remaining 5 groups of blocks, the first 10 trials of each of the eight 30-trial blocks were used to acquaint the subject with the paradigm; the remaining 20 trials for each of the 8 blocks were recorded and used as data. All of the subjects were run during the same period of time and all were instructed to respond as accurately and quickly as possible. The quantities measured and the methods of processing the raw data for Experiment 2 were the same as those in Experiment 1. The order of presentation of the fixed values of ISI was randomized over each group of blocks.

In order to relate results from these experiments to the work which has been done on the horizontal saccadic system by others, an experimental paradigm similar to the horizontal-vertical paradigm just described was employed. In this case, however, both the first and second target movements were horizontal. The responses of two subjects (J.H. and W.O.) were obtained for the following values of ISI: $50,100,200$ and $300 \mathrm{msec}$. The number of trials and the order of presentation were similar to the methods used in the horizontal-vertical case.

\section{RESULTS FOR EXPERIMENT 2}

The results expected from this experiment were basically the same as those of Experiment 1 if the subjects were not able to utilize the added information available to them in the form of fixed ISI and reduced choice. However, if the subjects were able to utilize this information, then the values obtained for $\mathrm{RT}_{2}$ should be significantly less than those obtained in Experiment 1. If preprogramming occurred in Experiment 1, the values of $\mathrm{RT}_{1}$ should also be affected. In this case, a decrease in $\mathrm{RT}_{1}$ in Experiment 2 would be expected because the number of choices has been reduced.

Figures 7, 8 and 9 are plots of $\mathrm{RT}_{1}$ vs. ISI, $\mathrm{RT}_{2}$ vs. ISI, and System Delay (as defined in Experiment 1) vs. ISI, respectively, for each of the 3 subjects. Each point on these plots represents the average of at least 40 experimental trials. It can be seen from Fig. 7 that there is little variation of $\mathrm{RT}_{1}$ as a function of ISI for all 3 of the subjects. The only difference among the 3 subjects are their individual mean reaction times.

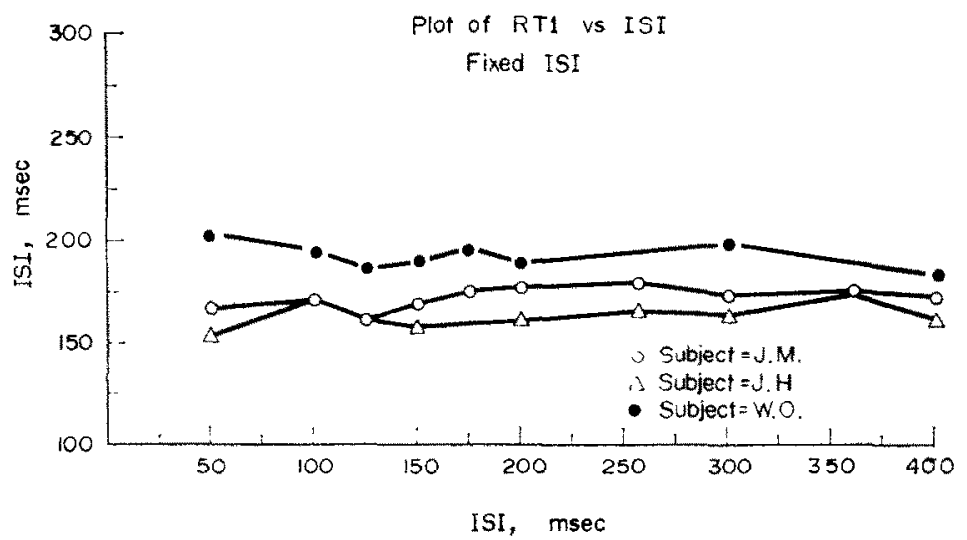

Fro. 7. Plot of RT, vs. ISI for Experiment 2. Note that one of the subjects, J.M., was not used in Experiment 1. The other two subjects, W.O. and J.H., were used in both Experiments 1 and 2 and the symbols used for their results in both experiments are the same throughout. Also note that the resuits presented here and in the remaining figures are plotted on an expanded scale in relation to Figs. 4, 5 and 6 . It can be seen that as in Fig. 4 there is little variation of $R T_{2}$ as a function of ISI. 


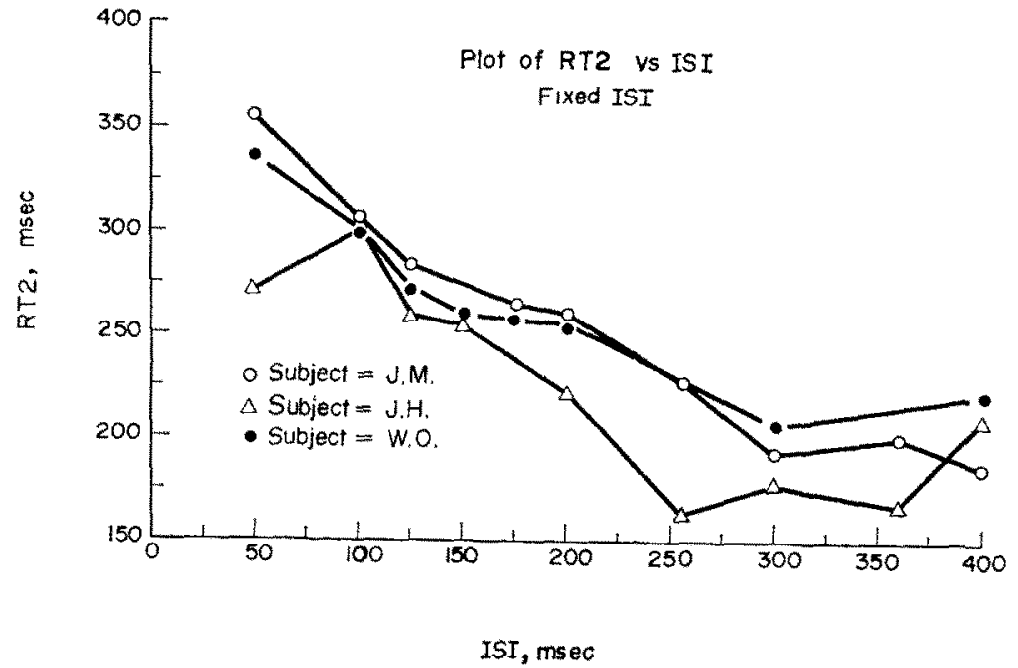

Fic. 8. Plot of $\mathrm{RT}_{2}$ vs. ISI for Experiment 2. As in Fig. 5, these results indicate the presence of the PRP and an interaction between the orthogonal saccadic systerns.

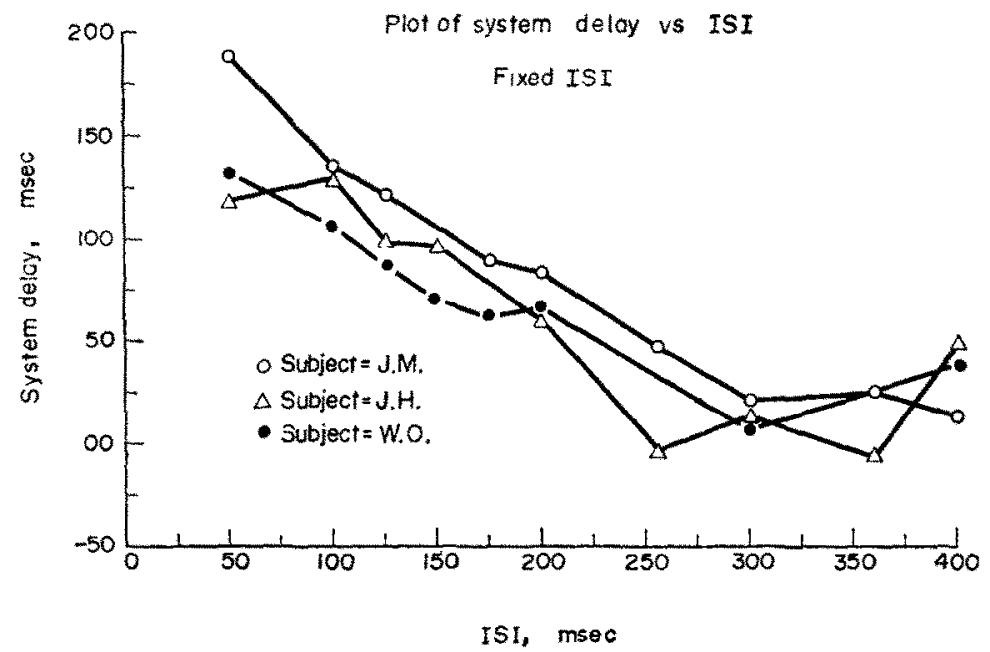

Fic. 9. Plot of System Delay vs. ISI for Experiment 2. As in Fig. 6, System Delay is not independent of ISI, thus indicating interaction of the horizontal and vertical saccadic systems.

The results obtained for Experiments 1 and 2 are almost identical for all of the dependent variables. This indicates that there is sufficient randomness introduced by the spatial uncertainty in the two-choice/two-choice paradigm to make it unpredictable. Thus, the two sets of results confirm each other. 
TABLE 1. COMPARISON OF RESULTS FOR HORIZONTAL-VERTICAL AND HORIZONTAL-HORIZONTAL EXPERIMENTS (ALL VALUES IN MSEC)

\begin{tabular}{|c|c|c|c|c|c|c|c|}
\hline \multirow[b]{2}{*}{ ISI } & \multirow[b]{2}{*}{$\mathrm{RT}_{1}(\mathrm{H}-\mathrm{V})$} & \multirow[b]{2}{*}{$\mathrm{RT}_{2}(\mathrm{H}-\mathrm{H})$} & \multirow[b]{2}{*}{$R T_{1}(H-V)$} & \multirow[b]{2}{*}{$\mathrm{RT}_{2}(\mathrm{H}-\mathrm{H})$} & \multicolumn{2}{|c|}{ System delay } & \multirow{2}{*}{$\begin{array}{c}\% \text { Incorrect } \\
(\mathrm{H}-\mathrm{H}) \\
\text { responses }\end{array}$} \\
\hline & & & & & $(\mathrm{H}-\mathrm{V})$ & $(\mathrm{H}-\mathrm{H})$ & \\
\hline \multicolumn{8}{|c|}{ Subject: J.H. } \\
\hline 50 & 154 & 160 & 272 & 185 & 118 & 25 & $67 \cdot 0$ \\
\hline 100 & 171 & 156 & 301 & 177 & 130 & 21 & $41 \cdot 5$ \\
\hline 200 & 161 & 176 & 223 & 156 & 62 & -20 & 5.5 \\
\hline 300 & 164 & 179 & 178 & 165 & 14 & -14 & 0.0 \\
\hline \multicolumn{8}{|c|}{ Subject: W.O. } \\
\hline 50 & 204 & 174 & 336 & 201 & 132 & 27 & 65.0 \\
\hline 100 & 195 & 175 & 301 & 198 & 106 & 23 & $8 \cdot 5$ \\
\hline 200 & 190 & 179 & 256 & 193 & 66 & 14 & $4 \cdot 25$ \\
\hline 300 & 199 & 174 & 207 & 172 & 8 & -2 & 0.0 \\
\hline
\end{tabular}

This table shows a comparison of results for the two subjects who were common to Experiment 2 and the horizontal-horizontal experiment. All values given are mean values. Values for $\mathrm{RT}_{1}(\mathrm{H}-\mathrm{V}), \mathrm{RT}_{2}(\mathrm{H}-\mathrm{V})$ and System Delay (H-V) were obtained from Experiment 2. Values for $R_{1}(H-H), R_{2}(H-H)$ and $S_{2}$ stem Delay $(\mathrm{H}-\mathrm{H})$ were obtained from the horizontal-horizontal experiment. Per cent incorrect responses were only reported for the $\mathrm{H}-\mathrm{H}$ case since there were no incorrect responses in the orthogonal cases. In particular, note the relationship between corresponding $\mathbf{R T}_{2}$ 's and System Delays. This comparison indicates that the process described by Experiments 1 and 2 is distinct from the properties of either saccadic system alone, but due to their interaction.

Table 1 is a comparison of the responses to the horizontal-vertical and horizontalhorizontal stimulus presentation paradigms. The horizontal-vertical results are from Experiment 1 . The results for the two paradigms differ substantially, especially for small values of ISI. These results indicate that the ISI has a significant influence on system delay for the horizontal-vertical paradigm, whereas the effect of ISI on system delay for the horizontal-horizontal paradigm is very small.

The horizontal-horizontal paradigm is similar to that employed by BeELER (1965). In our experiments no attempt was made to categorize the second response with respect to the first as Beeler did.

The results of the 2 paradigms differ in another important respect. For the horizontalvertical stimulus pairs there were no incorrect responses. However, the subjects frequently responded to the horizontal-horizontal stimulus pairs with only 1 saccade rather than 2 . This result agrees with that of WirerLess (1965).

One must conclude from these results that the response to orthogonal step pairs is significantly different from step pairs in the horizontal plane alone. The interaction of the horizontal and vertical saccadic systems introduces a delay which is dependent upon ISI. This delay is due to the interaction of the orthogonal saccadic systems and not the type of stimulus.

\section{SUMMARY}

The results of Experiments 1 and 2 indicate that the horizontal and vertical saccadic systems are complexly interrelated. The phenomenon of the PRP was observed in both experiments. The observed delay is due to the interaction of the horizontal and vertical saccadic systems. This interaction may be due to sensory information being processed in a parallel manner and motor activity being mediated by a serial processing stage. 


\title{
REFERENCES
}

BEELER, G. W., JR. (1965). Stochastic processes in the human eye movement control system. Ph.D. Thesis. California Institute of Technology.

Cook, G. (1965). Control systems study of the saccadic eye-movement mechanism. Sc.D. Thesis. Massachusetts Institute of Technology.

Feinstein, R. and Williams, W. J. (1968). A study of coupling between the horizontal and vertical eye movement systems. Proc. 21 st Annual Conf. Eng. in Med. and Biol., Houston, Texas.

Robinson, D. A. (1964). The mechanics of human saccadic eye movement. J. Physiol., Lond. 174, 245-264.

Robinson, D. A. (1965). The mechanics of human pursuit eye movement. J. Physiol., Lond. 180, 569-591.

Robinson, D. A. (1968). The oculomotor control system: A review. Proc. IEEE 56, 1032-1049.

SMITH, M. C. (1967). Theories of the pyschological refractory period. Psychol. Bull. 67, 202-213.

ST-CYR, G. T. and Fender, D. H. (1969). Nonlinearities of the human oculomotor system: Gain. Vision Res. 9, 1235-1246.

TAMLER, E., MARG, E., JAMPOlSky, A. and NAWRaRzki, I. (1959). Electromyography of human saccadic eye movements. A.M.A. Archs Ophthal. 73, 230-232.

Triggs, J. J. (1968). Capacity sharing and speeded reactions to successive signals. Report No. 9. Human Performance Center, University of Michigan, Ann Arbor, Michigan.

Von HoLST, E. (1954). Relations between the central nervous system and the peripheral organs. Br.J.physiol. Optics 154, 572-580.

WELFORD, A. T. (1952). The psychological refractory period and the timing of high-speed performanceA review and theory. Br. J. Psychol, 43, 2-19.

WeSTHEIMER, G. (1954). Eye movement responses to a horizontally moving visual stimulus. A.M.A. Archs Ophthal. 52, 932-941.

WhEeLESS, L. L. (1965). The effects of intensity on the eye movement control system. Ph.D. Thesis, University of Rochester, New York.

Wolfr, E. (1968). Anatomy of the Eye and Orbit, 6th Ed. W. B. Saunders, Philadelphia.

YouNG, L. R. (1962). A sampled data model for eye tracking movements. Sc.D. Thesis. Massachusetts Institute of Technology.

Young, L. R., ForSTER, J. D. and VAN HoutTe, N. (1968). A revised stochastic sampled data model of eye tracking movements. 4th Annual NASA-University Conference on Manual Control, Ann Arbor, Michigan.

Zuber, B. L. (1965). Physiological control of eye movements in humans. Ph.D. Thesis, Massachusetts Institute of 'Technology.

\begin{abstract}
The human oculomotor system has been studied by numerous people for well over half a century. Since the visual system is our primary sensory input channel, it is important for us to know how information is processed by the system. Most of the previous work on eye movements has been on modeling the horizontal eye movement control system.

In the present series of experiments, human subjects were given the task of tracking a spot of light which moved both horizontally and vertically. The temporal relationship of the horizontal and vertical eye movements was recorded using a light reflection technique. The results of these experiments indicate that the horizontal and vertical saccadic systems are complexly interrelated. The phenomenon of the Psychological Refractory Period was observed. The interaction of the orthogonal saccadic systems may be due to visual information being processed in a parallel manner and motor activity being mediated by a serial processing stage.
\end{abstract}

Résumé--De nombreuses études ont été consacrées au système oculomoteur humain depuis bien plus d'un- demi siècle. Comme le système visuel est notre principale source d'information sensorielle, il nous importe de connaitre le traitement de l'information dans ce système. La plupart des travaux antérieurs sur les mouvements des yeux ont recherché un modèle du système de côntrole du mouvement horizontal de l'oeil.

Dans la serie présente d'expériences, les sujets humains devaient suivre un point lumineux qui se déplaçait à la fois horizontalement et verticalement. On enregistrait par une technique de réflexion de lumière la relation temporelle des mouvements des yeux horizontaux et verticaux. Les expériences indiquent une interrelation complexe entre les systemes de saccades horizontal et vertical. On observe le phénomène de Période Réfractaire Psychologique. L'interaction des systèmes orthogonaux de saccades est peut-être due à un parallélisme dans le traitement de l'information visuelle, tandis que l'activité motrice est engendrée par un processus sériel. 
Zusammenfassung-Das okulomotorische System des Menschen wurde an zahlreichen Personen über gut ein halbes Jahrhundert untersucht. Da das visuelle System der Anfang unseres sensorischen Kanals ist, ist es für uns wichtig za wissen, wie Information vom System übertragen wird. Die meisten der früheren Arbeiten über Augenbewegungen überprüften die Horizontalbewegung des Auges.

In den vorliegenden Experimenten hatten die Versuchspersonen die Aufgabe, horizontal und vertikal bewegten Lichtpunkten zu folgen. Über Reflexionsmessungen wurde die zeitliche Abhangigkeit der horizontalen und vertikalen Augenbewegungen aufgezeichnet. Es ergab sich, $\mathrm{daB}$ die horizontalen und vertikalen Sakkaden in komplizierter Weise miteinander verknüpft sind. Das würde das Phänomen der psychologischen Refractärperiode beobachtet. Die Wechselwirkung des zueinander senkrechten Sakkadensystems könnte visuelle Information auf parallele Weise und motorische Aktivität in einer seriellen ProzeBfolge hervorrufen.

Резюме - Окуломоторная система человека изучалась многими исследователями в течение более чем полстолетия. Поскольку зрительная система является нашим основным сенсорным входным каналом, для нас важно знать как передается информация этой системой. Ботьшинство предтествукоиих работ моделировати контрольную систему горизонтального движения глаза.

В настоящей серии экспериментов, испытуемым-людям была предложена задача следить за световым пятном, которое движется как в горизональном, так и в вертикальном направлениях. Временные соотношения горизонтальных и вертикальных движений глаз регистрировалнсь с помощью техники светового отражения. Результаты этих экспериментов показывают, что горизонтальнаян вертикальная саккадическая системы находятся в сложных взаимоотнотениях. Наблюдался феномен пспхологического рефрактерного периода. Взаимодействие ортогональных саккадических систем может давать зрительнуюо информацию фунционируя параллельно, а двитательная активность будет опосредоваться серией фаз этого процесса. 